\title{
Effect of pattern and severity of respiratory muscle weakness on carbon monoxide gas transfer and lung volumes
}

\author{
N. Hart*, D. Cramer", S.P. Ward", A.H. Nickol*, J. Moxham ${ }^{\#}$, M.I. Polkey*, N.B. Pride*
}

Effect of pattern and severity of respiratory muscle weakness on carbon monoxide gas transfer and lung volumes. N. Hart, D. Cramer, S.P. Ward, A.H. Nickol, J. Moxham, M.I. Polkey, N.B. Pride. C ERS Journals Ltd 2002.

ABSTRACT: In clinical practice, an elevated carbon monoxide (CO) transfer coefficient $(\mathrm{KCO})$ and restrictive ventilatory defect are taken as features of respiratory muscle weakness (RMW). However, the authors hypothesised that both pattern and severity of RMW effect gas transfer and lung volumes.

Measurements of $\mathrm{CO}$ transfer and lung volumes were performed in patients with isolated diaphragm weakness $(n=10)$, inspiratory muscle weakness $(n=12)$, combined inspiratory and expiratory muscle weakness $(n=5)$ and healthy controls $(n=6)$.

Patients with diaphragm weakness and inspiratory muscle weakness had reduced total lung capacity (TLC) (83.6\% predicted and 68.9\% pred, respectively), functional residual capacity (FRC) $(83.9 \%$ pred and $83.6 \%$ pred) and transfer factor of the lung for CO $\left(T_{\mathrm{L}, \mathrm{CO})}(86.2 \%\right.$ pred and $66.2 \%$ pred) with increased $K C O(114.1 \%$ pred and $130.2 \%$ pred). Patients with combined inspiratory and expiratory muscle weakness had reduced TLC (80.9\% pred) but increased FRC $(109.9 \%$ pred) and RV $(157.4 \%$ pred $)$ with decreased $T \mathrm{~L}, \mathrm{CO}(58.0 \%$ pred) and $K \mathrm{CO}(85.5 \%$ pred $)$.

In patients with diaphragm weakness, the increase in carbon monoxide transfer coefficient was similar to that of normal subjects when alveolar volume was reduced. However, the increase in carbon monoxide transfer coefficient in inspiratory muscle weakness was often less than expected, while in combined inspiratory and expiratory muscle weakness, the carbon monoxide transfer coefficient was normal/reduced despite further reductions in alveolar volume, which may indicate subtle abnormalities of the lung parenchyma or pulmonary vasculature. Thus, this study demonstrates the limitations of using carbon monoxide transfer coefficient in the diagnosis of respiratory muscle weakness, particularly if no account is taken of the alveolar volume at which the carbon monoxide transfer coefficient is made.

Eur Respir J 2002; 20: 996-1002.
*Respiratory Muscle Laboratory, and ${ }^{\#}$ Lung Function Unit, Royal Brompton Hospital, and "Dept of Respiratory Medicine \& Allergy, Guy's, King's and St Thomas' School of Medicine, King's College Hospital, London, UK.

Correspondence: N. Hart

Respiratory Muscle Laboratory

Royal Brompton Hospital

Fulham Road

London

SW3 6NP

UK

Fax: 442073518939

E-mail: drnhart@aol.com

Keywords: Carbon monoxide transfer lung volumes

respiratory muscle weakness

Received: October 162001

Accepted after revision: January 14 2002

N. Hart was funded by the Dorothy Osbourne Legacy/Royal Brompton Hospital Trust Award and A.H. Nickol was funded by the British Lung Foundation.
Transfer factor of the lung for carbon monoxide (CO) $(T \mathrm{~L}, \mathrm{CO})$ is the product of the $\mathrm{CO}$ transfer coefficient $(\mathrm{KCO})$, which indicates the rate constant of $\mathrm{CO}$ uptake from the alveoli and the alveolar volume $(V \mathrm{~A})$ at which the measurement is made [1]. Many studies, including the original study by KROGH [1], have shown that if $\mathrm{CO}$ transfer is measured at submaximal $V$ A, the decline in $T \mathrm{~L}, \mathrm{CO}$ is partially offset by an increase in $\mathrm{KCO}$. In clinical practice, $\mathrm{CO}$ uptake is measured at total lung capacity (TLC), but many disease states associated with a reduced TLC often have coexistent intrapulmonary disease and, as a consequence, have a reduction in KCO. However, when the cause of the reduced TLC is extrapulmonary, a distinctive pattern may be found in which KCO is increased at full inflation and $V \mathrm{~A}$ is decreased, so that reductions in $T \mathrm{~L}, \mathrm{CO}$ are smaller than observed in intrapulmonary disease. The most obvious disorder simulating the effects of submaximal inflation is inspiratory muscle weakness without intrapulmonary disease. In an influential study of six patients [2], in which TLC was reduced due to severe isolated diaphragm weakness, a relatively benign disease in the absence of other cardiopulmonary disease [2], there was a reduction in mean $T \mathrm{~L}, \mathrm{CO}(65 \%$ predicted $)$ but an increase in mean KCO (128\% pred). As a result, in clinical practice, a raised $K \mathrm{CO}$ associated with a restrictive ventilatory defect is often taken as a feature of respiratory muscle weakness [3].

However, there have been no systematic studies that have examined $\mathrm{CO}$ transfer and lung volumes across a range of neuromuscular disorders causing different patterns of respiratory muscle weakness. The current authors hypothesised that since pattern and severity of respiratory muscle weakness can influence the pulmonary complications of neuromuscular diseases [2, 4], this would also affect $\mathrm{CO}$ transfer, subdivisions of lung volume and dynamic lung compliance ( $C \mathrm{~L}$,dyn). To investigate this hypothesis, three groups of patients were studied: isolated unilateral and bilateral diaphragm weakness; generalised inspiratory muscle weakness; and combined inspiratory and expiratory muscle weakness. In addition, CO transfer at TLC and at submaximal lung volumes were measured in six 
normal subjects, by restricting inspiration and expiration during the manoeuvres to simulate the expected effects of acute combined inspiratory and expiratory muscle weakness in patients.

\section{Methods}

\section{Patients}

A total of 139 patients were referred to the authors' laboratory for respiratory muscle function assessment over a 28-month period. A standard protocol was followed for all patients [5].

\section{Inclusion criteria}

Patients were included if the right and/or left twitch transdiaphragmatic pressure $(P \mathrm{di}, \mathrm{tw})$ was $<3.5 \mathrm{cmH}_{2} \mathrm{O}$ (see below for methods). Such patients were further subclassified into isolated unilateral and bilateral diaphragm weakness with: preserved global respiratory muscle strength (maximal sniff oesophageal pressure ( $P$ oes,sniff) $>50 \mathrm{cmH}_{2} \mathrm{O}$ and maximal cough gastric pressure $(P$ gas,cough $\left.)>70 \mathrm{cmH}_{2} \mathrm{O}\right)$; inspiratory muscle weakness with preserved expiratory muscle strength $\left(P\right.$ oes, sniff $<50 \mathrm{cmH}_{2} \mathrm{O}$ and $P$ gas,cough $\left.>70 \mathrm{cmH}_{2} \mathrm{O}\right)$; and combined inspiratory and expiratory muscle weakness with inspiratory and expiratory muscle weakness ( $P$ oes,sniff $<50 \mathrm{cmH}_{2} \mathrm{O}$ and $P$ gas,cough $<70 \mathrm{cmH}_{2} \mathrm{O}$ ).

\section{Exclusion criteria}

The authors excluded patients with a current smoking history, a maximum expiratory flow/volume curve indicative of airways disease, a forced expiratory volume in one second (FEV1)/forced vital capacity (FVC) ratio of $<0.7$, symptoms or signs of cardiac disease or failure, parenchymal lung disease identified on clinical grounds or chest radiography, and patients unable to perform full lung function testing.

\section{Pulmonary function tests}

Pulmonary function assessment included FEV1, FVC, TLC, functional residual capacity (FRC) and residual volume (RV) by body plethysmography. $T \mathrm{~L}, \mathrm{CO}$ and $\mathrm{KCO}$ were measured by the single-breath method [6] at full inflation (TLC) in the patients and at TLC and submaximal volumes in the normal subjects. TL,CO and KCO were corrected for haemoglobin concentration [7]. Spirometry, lung volume and $T \mathrm{~L}, \mathrm{CO}$ predicted values were taken from the European Coal and Steel Community [8]. The KCO regression equations used for males and females were $(-0.013 \times$ age $)+2.20$ and $(-0.007 \times$ age $)+2.07$, respectively [9].

\section{Pressure measurements}

$P_{\text {oes }}$ and $P_{\text {gas }}$ were measured using appropriately positioned balloon catheters (Ackrad Laboratories,
Cranford, NJ, USA). $P$ di was obtained by online subtraction of $P_{\text {oes }}$ from $P$ gas. Pressures were measured using differential pressure transducers (Validyne, Northridge, CA, USA) and amplified before passing to a computer (Apple Computer Inc., Cupertino, CA, USA) via an analogue/digital board. Data acquisition and analysis was performed using LabVIEW ${ }^{\mathrm{TM}_{4}} 4$ software (National Instruments, Austin, TX, USA). All signals were sampled at $100 \mathrm{~Hz}$.

\section{Respiratory muscle tests}

All participants performed at least 10 sniff and five cough manoeuvres, from FRC and TLC respectively, and maximum sniff $P_{\text {oes }}$ and cough $P$ gas values were recorded. Subjects also performed at least three maximal inspiratory and expiratory efforts against a closed airway at FRC and TLC, and the highest values maintained over $1 \mathrm{~s}$ at the mouth were recorded (maximum inspiratory pressure at residual volume $(P I, \max )$ and maximum expiratory pressure $(P$ E,max $)$, respectively). Predicted values were calculated for $P \mathrm{I}, \max$ and $P \mathrm{E}$,max [10]. Assessment of unilateral diaphragm function was performed using magnetic phrenic nerve stimulation [11].

\section{Dynamic compliance}

$C$ L,dyn was calculated during resting breathing by dividing tidal volume by the difference in $P$ oes at points of zero flow. Age-matched control values for $C \mathrm{~L}$,dyn were taken from the laboratory database.

\section{Normal studies}

In six normal subjects, the $K \mathrm{CO}$ and $T \mathrm{~L}, \mathrm{CO}$ were measured at TLC and at submaximal lung volumes. Subjects mimicked expiratory and inspiratory muscle weakness by expiring to $50 \%$ of expiratory reserve volume and inspiring to $50 \%$ of inspiratory capacity using visual feedback. This was termed the "simulated combined muscle weakness group".

\section{Statistical analysis}

An analysis of variance (ANOVA) (Fisher's) test was used to evaluate the differences between the groups. Differences between the $C$ L,dyn of agematched controls and patients were assessed using unpaired t-tests. A p-value of $<0.05$ was considered statistically significant.

\section{Results}

From the 139 patients referred, a total of 27 patients were identified as suitable for analysis. Diagnoses included neuralgic amyotrophy with isolated unilateral and bilateral diaphragm weakness, limb girdle muscular dystrophy, Charcot-Marie-Tooth 
Table 1. - Invasive and noninvasive tests of respiratory muscle strength

\begin{tabular}{|c|c|c|c|c|}
\hline & Controls & UDW/BDW & IMW & CMW \\
\hline Age yrs & $35.3 \pm 10.2$ & $54.0 \pm 16.8^{*}$ & $66.2 \pm 11.9^{*}$ & $39.2 \pm 14.3$ \\
\hline Subjects n (female) & $6(1)$ & $10(0)$ & $12(1)$ & $5(3)$ \\
\hline$P_{\text {oes, sniff }} \mathrm{cmH}_{2} \mathrm{O}$ & $129.9 \pm 26.8$ & $85.5 \pm 24.7 *$ & $34.4 \pm 8.9^{*}$ & $39.2 \pm 11.3^{*}$ \\
\hline$P$ gas,cough $\mathrm{cmH}_{2} \mathrm{O}$ & $175.6 \pm 58.9$ & $229.6 \pm 61.0$ & $175.8 \pm 70.3$ & $48.3 \pm 18.3^{*}$ \\
\hline \multirow[t]{2}{*}{$P \mathrm{I}, \max \%$ pred $\left(\mathrm{cmH}_{2} \mathrm{O}\right)$} & $91.8 \pm 17.6$ & $71.5 \pm 18.9^{*}$ & $28.1 \pm 11.9^{*}$ & $41.7 \pm 22.0 *$ \\
\hline & $(112.0 \pm 27.6)$ & $(82.2 \pm 15.9)$ & $(29.5 \pm 10.3)$ & $(33.8 \pm 15.8)$ \\
\hline \multirow[t]{2}{*}{$P$ E,max $\%$ pred $\left(\mathrm{cmH}_{2} \mathrm{O}\right)$} & $99.3 \pm 31.5$ & $77.8 \pm 14.9$ & $63.6 \pm 32.5^{*}$ & $32.0 \pm 21.4^{*}$ \\
\hline & $(143.1 \pm 49.6)$ & $(110.4 \pm 30.0)$ & $(90.9 \pm 48.0)$ & $(32.4 \pm 16.3)$ \\
\hline
\end{tabular}

Data are presented as mean \pm SD unless otherwise stated. UDW/BDW: isolated unilateral and bilateral diaphragm weakness; IMW: generalised inspiratory muscle weakness; CMW: combined inspiratory and expiratory muscle weakness; $P$ oes,sniff: maximum sniff oesophageal pressure; $P$ gas,cough: maximum cough gastric pressure; $P \mathrm{I}$,max: maximum inspiratory pressure averaged over $1 \mathrm{~s}$; \% pred: percentage of predicted normal value; $P$ E,max: maximum expiratory pressure averaged over $1 \mathrm{~s}$. *: significant difference from control group, $\mathrm{p}<0.05$.

disease, Becker's muscular dystrophy, myotonic dystrophy and anterior horn cell disease. Six out of 10 patients with isolated diaphragm weakness, six out of 12 patients with inspiratory muscle weakness and three out of five patients with combined muscle weakness were nonsmokers, the remainder were exsmokers.

\section{Respiratory muscle tests}

Differences in $P_{\text {oes,sniff }}$ between the groups were mirrored in the per cent predicted PI,max. However, per cent predicted $P$ E,max were below the control values in all three patients groups, although the lowest values were in the combined inspiratory and expiratory muscle weakness group, which was the only group with reduced $P$ gas,cough (table 1).

\section{Lung volumes}

All patient groups had reduced vital capacity (VC) and TLC (table 2). Patients with unilateral and bilateral diaphragm weakness and inspiratory muscle weakness had a normal RV with reduced FRC. In patients with combined inspiratory and expiratory muscle weakness, RV was increased and FRC preserved. The FEV1/FVC ratio was higher in combined inspiratory and expiratory muscle weakness than inspiratory muscle weakness, probably reflecting the expiratory muscle weakness and increased RV.

\section{Carbon monoxide gas transfer}

The per cent predicted $V$ A was reduced in all four groups. Mean KCO was increased in inspiratory muscle weakness, unilateral and bilateral diaphragm weakness and simulated combined inspiratory and expiratory muscle weakness groups, but reduced in the combined inspiratory and expiratory muscle weakness group (table 3 ). As expected, KCO increased as $V \mathrm{~A}$ declined in the healthy subjects. To accommodate for the effect of $V \mathrm{~A}$, the individual values of $K C O$ and $V \mathrm{~A}$, expressed as percentages of the standard reference values, were plotted against each other and compared with reference values of $\mathrm{KCO}$ adjusted for lung volume [12] (fig. 1). Unilateral and bilateral diaphragm weakness patients and simulated combined inspiratory and expiratory muscle weakness subjects had $K \mathrm{CO}$ values close to those predicted at submaximal $V \mathrm{~A}$ in normal subjects. Inspiratory muscle weakness patients, who had the lowest mean $V \mathrm{~A}$, all had elevated $\mathrm{KCO}$ values using the standard reference

Table 2. - Effect of different patterns of respiratory muscle weakness on lung volumes and spirometry

\begin{tabular}{|c|c|c|c|c|}
\hline & Controls & UDW/BDW & IMW & CMW \\
\hline VC \% pred (L) & $\begin{array}{l}101.8 \pm 14.7 \\
(5.47 \pm 1.37)\end{array}$ & $\begin{array}{c}76.4 \pm 7.2^{*} \\
(2.97 \pm 1.14)\end{array}$ & $\begin{array}{l}49.6 \pm 13.6^{*, \#} \\
(1.98 \pm 0.64)\end{array}$ & $\begin{array}{l}50.5 \pm 15.6^{*}, \# \\
(2.03 \pm 0.74)\end{array}$ \\
\hline TLC $\%$ pred (L) & $\begin{array}{l}107.3 \pm 7.0 \\
(7.51 \pm 1.15)\end{array}$ & $\begin{array}{c}83.6 \pm 11.2 * \\
(5.87 \pm 1.52)\end{array}$ & $\begin{array}{l}68.9 \pm 12.1^{*, \#} \\
(4.60 \pm 0.95)\end{array}$ & $\begin{array}{l}80.9 \pm 13.0 * \\
(4.94 \pm 1.74)\end{array}$ \\
\hline FRC $\%$ pred $(\mathrm{L})$ & $\begin{array}{c}101.1 \pm 13.9 \\
(3.65 \pm 0.68)\end{array}$ & $\begin{array}{c}83.9 \pm 15.1 \\
(3.06 \pm 0.70)\end{array}$ & $\begin{array}{c}83.6 \pm 17.2 \\
(2.94 \pm 0.68)\end{array}$ & $\begin{array}{l}109.9 \pm 29.2^{\#,} \\
(3.45 \pm 1.35)\end{array}$ \\
\hline $\mathrm{RV} \%$ pred $(\mathrm{L})$ & $\begin{array}{l}117.3 \pm 17.0 \\
(2.02 \pm 0.47)\end{array}$ & $\begin{array}{l}102.6 \pm 20.6 \\
(2.52 \pm 0.47)\end{array}$ & $\begin{array}{c}103.7 \pm 23.4 \\
(2.55 \pm 0.63)\end{array}$ & $\begin{array}{l}157.4 \pm 48.6^{*, \#,} \\
(2.89 \pm 1.49)\end{array}$ \\
\hline FEV1/FVC \% & $83.4 \pm 6.0$ & $74.4 \pm 4.1^{*}$ & $79.4 \pm 5.0^{\#}$ & $90.5 \pm 2.6^{*}, \#$ \\
\hline
\end{tabular}

Data are presented as mean \pm SD. UDW/BDW: isolated unilateral and bilateral diaphragm weakness; IMW: generalised inspiratory muscle weakness; CMW: combined inspiratory and expiratory muscle weakness; VC: vital capacity; $\%$ pred: percentage of predicted normal value; TLC: total lung capacity; FRC: functional residual capacity; RV: residual volume; FEV1/FVC: forced expiratory volume in one second, normalised for the forced vital capacity. *: significant difference from control group, $\mathrm{p}<0.05$; ${ }^{\#}$ : significant difference from UDW/BDW group, $\mathrm{p}<0.05$; : significant difference from IMW group, $\mathrm{p}<0.05$. 
Table 3. - Effect of different patterns of respiratory muscle weakness on carbon monoxide transfer

\begin{tabular}{|c|c|c|c|c|c|}
\hline & Controls & sCMW & UDW/BDW & IMW & CMW \\
\hline KCO \% pred & $89.3 \pm 8.7$ & $115.3 \pm 7.9^{*}$ & $114.1 \pm 15.5^{*}$ & $130.2 \pm 23.2^{*}$, & $85.5 \pm 9.4^{\#, \S}$ \\
\hline$T \mathrm{~L}, \mathrm{CO} \%$ pred & $95.2 \pm 8.2$ & $80.0 \pm 7.7^{*}$ & $86.2 \pm 8.6$ & 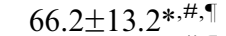 & $58.0 \pm 11.9^{*, \#, \emptyset}$ \\
\hline$V \mathrm{~A} \%$ pred & $108.1 \pm 8.0$ & $70.3 \pm 4.9 *$ & $79.9 \pm 11.0 *$ & 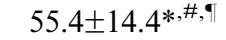 & $71.9 \pm 14.6^{*, \S}$ \\
\hline
\end{tabular}

Data are presented as mean \pm SD. sCMW: normal subjects simulating combined inspiratory and expiratory muscle weakness; UDW/BDW: isolated unilateral and bilateral diaphragm weakness; IMW: generalised inspiratory muscle weakness; CMW: combined inspiratory and expiratory muscle weakness; KCO: carbon monoxide transfer coefficient; \% pred: percentage of predicted standard reference value; $T$ L,CO: transfer factor of the lung for carbon monoxide; $V$ A: alveolar volume. *: significant difference from control group, $\mathrm{p}<0.05 ;{ }^{\#}$ : significant difference from sCMW group, $\mathrm{p}<0.05$; ${ }^{\text {? }}$ : significant difference from UDW/BDW group, $\mathrm{p}<0.05$; ' : significant difference from IMW group, $\mathrm{p}<0.05$. The KCO, $T$ L, CO and $V \mathrm{~A}$ in the stimulated CMW group are expressed as percentage of the values obtained during standard test CO transfer measurement at TLC.

values but in many instances, this increase was less than predicted from the model. In striking contrast, the patients in the combined inspiratory and expiratory muscle weakness group all had normal or even reduced $K C O$ standard reference values.

\section{Dynamic compliance}

$C \mathrm{~L}$,dyn values were lower in inspiratory muscle weakness and combined inspiratory and expiratory muscle weakness groups than in the unilateral and bilateral diaphragm weakness group (table 4). Although the values of $C \mathrm{~L}$, dyn in inspiratory muscle weakness and combined inspiratory and expiratory muscle weakness were lower than in the age-matched controls, paralleling the reductions in $\mathrm{VC}$, there was no difference between the inspiratory muscle weakness and combined inspiratory and expiratory muscle weakness patients $(\mathrm{p}=0.75)$.

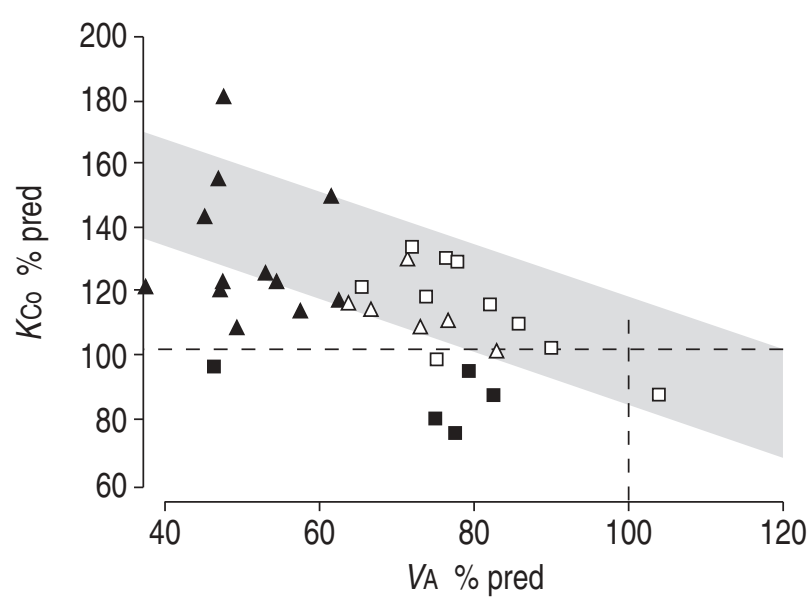

Fig. 1.-Plot of carbon monoxide transfer coefficient $(K \mathrm{CO})$ against alveolar volume $(V \mathrm{~A})$, both expressed as a percentage of predicted standard reference value ( $\%$ pred $)$, in patients with inspiratory muscle weakness $(\boldsymbol{\Delta})$, combined inspiratory and expiratory muscle weakness (ם), unilateral and bilateral diaphragm weakness $(\square)$, and in the normal subjects simulating combined muscle weakness $(\triangle)$. The shaded area (mean \pm SD) shows the $K C \mathrm{CO}$ plotted against $V \mathrm{~A}$ as a per cent of the $V \mathrm{~A}$ value at total lung capacity and at different levels of alveolar expansion in healthy middle-aged subjects [12]. One-hundred per cent predicted values for $K \mathrm{CO}$ and $V$ A are represented as dashed lines.

\section{Discussion}

In this study, the authors confirm that $\mathrm{KCO}$ is increased, compared to standard reference values, in patients with inspiratory muscle weakness and isolated unilateral and bilateral diaphragm weakness, and that the increase in KCO is inversely related to the decrease in lung volume. However, this increase in $K \mathrm{CO}$ is less than would be predicted for the decrease in $V \mathrm{~A}$ in many of the patients with inspiratory muscle weakness. In the patients with combined inspiratory and expiratory muscle weakness, the KCO is unexpectedly normal or even reduced compared to standard reference values.

\section{Critique of the method}

Selection criteria for patients. One limitation of the study is that only 27 patients with "pure" respiratory muscle weakness were eligible for analysis from the 139 consecutive patients studied. This was partly a result of the strict categorisation used to identify specific groups of patients with differing patterns and severities of inspiratory and expiratory muscle dysfunction, and partly because care was taken to avoid confounding variables, such as the presence of smoking-related lung disease, which would influence gas transfer and lung volumes.

\section{Classification of patient groups}

A classification system with arbitrary limits was used to subdivide the patients. Measurement of $P$ di,tw

Table 4.-Comparison of dynamic lung compliance ( $C$, dyn) between patients and age-matched controls (AMC)

\begin{tabular}{|c|c|c|c|}
\hline & UDW/BDW & IMW & CMW \\
\hline $\begin{array}{l}C \mathrm{~L} \text {,dyn patients } \\
\mathrm{mL} \cdot \mathrm{cmH}_{2} \mathrm{O}^{-1}\end{array}$ & $123 \pm 71$ & $87 \pm 32$ & $81 \pm 35$ \\
\hline $\begin{array}{l}\mathrm{CL} \text {,dyn } \mathrm{AMC}^{\mathrm{mL} \cdot \mathrm{cmH}_{2} \mathrm{O}^{-1}}\end{array}$ & $160 \pm 37$ & $153 \pm 32$ & $190 \pm 92$ \\
\hline p-value & 0.2 & 0.0002 & 0.05 \\
\hline
\end{tabular}

Data are presented as mean \pm SD unless otherwise stated. UDW/ BDW: isolated unilateral and bilateral diaphragm weakness; IMW: generalised inspiratory muscle weakness; CMW: combined inspiratory and expiratory muscle weakness. 
in response to phrenic nerve stimulation represents the only method for evaluation of diaphragm function, which is independent of the patients' aptitude and volition. All patients had evidence of severe unilateral and bilateral diaphragm weakness, as judged by magnetic phrenic nerve stimulation. The authors could have achieved further subclassification using $P \mathrm{I}, \max$ and $P$ E,max, but the normal ranges for these tests are wide [13] and a low $P$ I,max or $P$ E,max value does not distinguish between weakness and poor technique, particularly in patients with neuromuscular disease [4]. This problem is also demonstrated by a previous study by the current group [14], which reported patients studied prior to those in the present series, where it was found that of 30 patients with low $P$ I,max values, 10 had $P_{\text {oes, sniff values }}>80 \mathrm{cmH}_{2} \mathrm{O}$, excluding inspiratory muscle weakness. Thus, for the patient population in this study, the authors considered $P_{\text {oes,sniff }}$ and $P$ gas,cough to offer a more accurate subclassification than $P \mathrm{I}$,max and $P$ E,max.

Cough gastric pressure or cough oesophageal pressure? In the current authors' laboratory, expiratory muscle strength is measured as $P$ gas,cough because they have previously shown that this has a functional correlate with an effective cough [4, 15]. The authors acknowledge that the present hypothesis might have served more usefully by reporting $P_{\text {oes,cough }}$ because transpulmonary pressure is the driving pressure for flow and volume changes during a maximal cough. However, unpublished data from the current group suggests that $P$ di,cough is $<20 \%$ of the amplitude of $P$ gas,cough in $80 \%$ of normal subjects, so that $P_{\text {oes,cough }}$ is numerically similar to $P$ gas,cough, and this proportion is likely to be higher in patients with diaphragm weakness. Thus, the authors doubt whether a classification based on $P_{\text {oes, }}$ cough would alter the conclusions of the present study.

\section{Significance of the findings}

Effect of the pattern of respiratory muscle weakness on carbon monoxide transfer. Many authors, dating back to KROGH [1] in 1915, have shown an increase in KCO in normal subjects with submaximal inflation of the lungs. Stam et al. [12] demonstrated that in healthy subjects, the increase in $\mathrm{KCO}$ as lung volume decreases with submaximal inflation is linearly related to the fall in $V$ A. This implies a rise in the ratio between the membrane diffusing capacity $(D \mathrm{~m})$ and $V \mathrm{~A}$ and/or the pulmonary capillary blood volume $\left(Q_{\mathrm{c}}\right)$ and $V \mathrm{~A}$ as lung volume falls. As $V$ A decreases in normal subjects, $D \mathrm{~m} / V \mathrm{~A}$ remains almost constant and the rise in $K \mathrm{CO}$ is due to a rise in the $Q \mathrm{c} / V \mathrm{~A}$ ratio [3].

In agreement with earlier studies, the $K C O$ was increased in the normal subjects when lung expansion was restricted to $50 \%$ inspiratory capacity. The increase in KCO observed in unilateral and bilateral diaphragm weakness patients was appropriate for the relatively small reductions in TLC and $V \mathrm{~A}$, confirming the findings of the original study of LAROCHE et al. [2]. Although a subsequent report of patients with unilateral and bilateral diaphragm weakness showed a smaller increase in $\mathrm{KCO}(109 \%$ pred), there was a greater incidence of positive smoking history and airways obstruction in this study that could have offset the rise in KCO [16]. In the current study, patients with combined inspiratory and expiratory muscle weakness had normal or even decreased KCO values (compared to standard reference values), while patients with inspiratory muscle weakness had variable increases in $K C O$, which was often less than predicted at a similar $V A$ in normal subjects (fig. 1 and table 3). The increase in $K C O$ in normal subjects is dependent on the $V$ A at which the breath is held and the $\mathrm{CO}$ transfer measured. Furthermore, provided gas mixing of the inspired CO-helium mixture with resident gas is complete, an increase in $\mathrm{RV}$ should itself have no effect on $\mathrm{KCO}$, which was confirmed in the normal subjects simulating combined inspiratory and expiratory muscle weakness. However, in addition to the increase in $\mathrm{RV}$, the patients with combined inspiratory and expiratory muscle weakness had reduced lung compliance with probable unequal distribution of ventilation throughout the lungs, which could contribute to the reduced increase in KCO.

Since the polio epidemics of the 1950s, lung and chest wall compliance have been known to be reduced with chronic neuromuscular weakness, and VC is reduced more than can be accounted for simply by truncation of the inspiratory and/or expiratory extremes of the pressure/volume curve $[17,18]$. The current authors found that inspiratory muscle weakness and combined inspiratory and expiratory muscle weakness groups had the most impairment of VC and the lowest compliance values. The cause of this decrease in lung compliance remains unknown; changes in alveolar surfactant [19], stiffening of alveolar elastic fibres [20] and microatelectasis [19] have all been proposed, although no evidence of lung atelectasis has been found on high-resolution computerised tomography [20].

Another possible explanation for the reduced increase in $K \mathrm{CO}$ is a reduction in $Q_{\mathrm{c}}$ in the patients in this study with combined inspiratory and expiratory muscle weakness, all of whom had advanced disease. Four of the five patients had been started on nocturnal ventilation to treat ventilatory failure, and the fifth patient had borderline abnormal arterial oxygen $\left(\mathrm{O}_{2}\right)$ and carbon dioxide $\left(\mathrm{CO}_{2}\right)$ tensions. Therefore, the authors speculate that hypoxaemia and hypercapnia could have increased pulmonary vascular tone and induced pulmonary hypertension [21] and possibly reduced $Q$ c. This hypothesis could also explain the difference between the current study and that of DEMEDTs et al. [22], which reported the KCO to be moderately increased in patients with combined muscle weakness. However, the patients in that study had no abnormality of gas exchange and only a moderate reduction in TLC. In addition, the $\mathrm{KCO}$ in the asymptomatic patients of the study of DEMEDTs et al. [22] was appropriate for the level of lung inflation and thus, pulmonary vasculature changes would not have been expected to be present. It may be of interest to monitor the KCO of patients after a period of nocturnal ventilation to assess 
whether changes in KCO follow the improvements in arterial $\mathrm{O}_{2}$ and $\mathrm{CO}_{2}$. This is supported by a recent study by SCHÖNHOFER et al. [23], who reported that effective long-term noninvasive mechanical ventilation in patients with restrictive lung disease reduces pulmonary artery pressure. To the current authors' knowledge, there are no other studies of $K C O$ and $V$ A in chronic neuromuscular disease, although a strong relationship exists between the reduction in $V \mathrm{~A}$ and the increase in KCO in patients with scoliosis [24]. Therefore, in clinical practice, a subnormal rise in $K C O$ at reduced $V \mathrm{~A}$ would only be detected by comparing $K \mathrm{CO}$ with values appropriate for the reduced $V \mathrm{~A}$, because the values of KCO usually remain within the standard reference range (fig. 1).

Effect of the pattern of respiratory muscle weakness on lung volumes. It is well established that weakness of the respiratory muscles causes a restrictive ventilatory defect with a reduction in TLC. However, the resting end expiratory position (FRC) in patients with respiratory muscle weakness can be decreased [19, 25-27], normal [28, 29] or increased [30], while RV can be normal [19, 27] or increased [22, 28-30]. To examine whether these differences could be due to differences in the distribution of respiratory muscle weakness, the current authors analysed values of FRC and RV in eight studies $[2,19,22,30-34]$ that have reported both lung volumes and inspiratory and/or expiratory muscle function. In patients with inspiratory muscle weakness there was a reduction in FRC (mean decrease -21\%) with a near normal RV (mean decrease $-6.6 \%$ ), but in patients with combined respiratory muscle weakness, the FRC was near normal (mean decrease $-4.8 \%$ ) and the RV was increased (mean increase $+30.9 \%$ ). This concurs with the data in this study (table 2), suggesting that the pattern of respiratory muscle weakness is a determining factor for the subdivisions of lung volume.

Effect of the severity of respiratory muscle weakness. Patients with isolated diaphragm weakness had near normal lung function and the increase in $K \mathrm{CO}$ was appropriate for the reduction in $V \mathrm{~A}$ (fig. 1). The preservation of sufficient extradiaphragmatic inspiratory muscle function appears to limit the development of parenchymal or pulmonary vasculature abnormalities as judged by a near normal $C \mathrm{~L}$,dyn and an elevated $\mathrm{KCO}$.

In conclusion, while patients with inspiratory muscle weakness and reduced total lung capacity have an increase in carbon monoxide transfer coefficient compared to the standard reference values, patients with combined inspiratory and expiratory muscle weakness frequently have carbon monoxide transfer coefficient values that are normal or lower than the standard reference values. In addition, when the carbon monoxide transfer coefficient is normalised for alveolar volume, many patients with inspiratory muscle weakness and all of the present patients with combined inspiratory and expiratory muscle weakness have lower carbon monoxide transfer coefficient values than would be predicted from the alveolar volume. These observations demonstrate the limitation of using carbon monoxide transfer coefficient to support the diagnosis of respiratory muscle weakness and may also indicate subtle abnormalities in the lung parenchyma or pulmonary vasculature. In order to detect such changes, the carbon monoxide transfer coefficient should be compared to values observed in normal subjects at a similar alveolar volume.

Acknowledgements. The authors would like to thank J.M.B. Hughes for his knowledge and insight, which contributed to preparation of this manuscript.

\section{References}

1. Krogh M. The diffusion of gases through the lungs. J Physiol 1915; 49: 271-296.

2. Laroche CM, Carroll N, Moxham J, Green M. Clinical significance of severe isolated diaphragm weakness. Am J Respir Crit Care Med 1988; 138: $862-866$

3. Hughes JMB, Pride NB. In defence of the carbon monoxide transfer co-efficient KCO (TL/VA). Eur Respir J 2001; 17: 168-174.

4. Polkey MI, Lyall RA, Green M, Leigh PN, Moxham J. Expiratory muscle function in amyotrophic lateral sclerosis. Am J Respir Crit Care Med 1998; 158: 734 741.

5. Hart N, Polkey MI. Investigation of respiratory muscle function. Clin Pulm Med 2001; 8: 180-187.

6. Ogilvie C, Forster R, Blakemore W, Morton J. A standardised breath holding technique for the clinical measurement of the diffusing capacity of the lung for carbon monoxide. J Clin Invest 1957; 36: 1-17.

7. Cotes JE, Dabbs J, Elwood P, Hall A, McDonald A, Saunders M. Iron-deficiency anaemia: its effect on transfer factor for the lung (diffusing capacity) and ventilation and cardiac frequency during submaximal exercise. Clin Sci 1972; 42: 325-335.

8. Quanjer P, Tammeling G, Cotes J, Pedersen O, Peslin $\mathrm{R}$, Yernault J. Standardised lung function testing, lung volumes and forced ventilatory flows. Eur Respir $J$ 1993; 6: 5-40.

9. Cotes JE. Lung function: assessment and application in medicine. 5th Edn. Oxford, Blackwell Scientific Publications, 1993.

10. Bruschi C, Cerveri I, Zoia MC, et al. Reference values of maximal respiratory mouth pressures: a populationbased study. Am Rev Respir Dis 1992; 146: 790-793.

11. Mills GH, Kyroussis D, Hamnegard C-H, Wragg S, Moxham J, Green M. Unilateral magnetic stimulation of the phrenic nerve. Thorax 1995; 50: 1162-1172.

12. Stam H, Hrachovina V, Stijnen T, Versprille A. Diffusing capacity dependent on lung volume and age in normal subjects. J Appl Physiol 1994; 76: 23562363.

13. Black LF, Hyatt RE. Maximal respiratory pressures: normal values and relationships to age and sex. $\mathrm{Am}$ Rev Respir Dis 1969; 99: 696-702.

14. Hughes PD, Polkey MI, Kyroussis D, Hamnegard C-H, Moxham J, Green M. Measurement of sniff nasal and diaphragm twitch mouth pressure in patients. Thorax 1998; 53: 96-100.

15. Chetta A, Harris ML, Lyall RA, et al. Whistle mouth pressure as test of expiratory muscle strength. Eur Respir J 2001; 17: 688-695. 
16. Mulvey DA, Aquilina RJ, Elliot MW, Moxham J, Green M. Diaphragmatic dysfunction in neuralgic amyotrophy: an electrophysiological evaluation of 16 patients presenting with dyspnoea. Am Rev Respir Dis 1993; 147: 66-71.

17. DeTroyer A, Borenstein S, Cordier R. Analysis of volume restriction in patients with respiratory muscle weakness. Thorax 1980; 35: 603-610.

18. Estenne M, Heilporn A, Delhez L, Yernault Y-C, De Troyer A. Chest wall stiffness in patients with chronic respiratory muscle weakness. Am Rev Respir Dis 1983; 128: 1002-1007.

19. Gibson GJ, Pride NB, Newsom-Davis J, Loh L. Pulmonary mechanics in patients with respiratory muscle weakness. Am Rev Respir Dis 1977; 115: 389395.

20. Estenne M, Gevenois PA, Kinnear W, Soudon P, Heilporn A, De Troyer A. Lung volume restriction in patients with chronic respiratory muscle weakness: the role of microatelectasis. Thorax 1993; 48: 698-701.

21. Hasleton PS, Heath D, Brewer DB. Hypertensive pulmonary vascular disease in states of chronic hypoxia. J Pathol Bacteriol 1968; 95: 431-440.

22. Demedts M, Beckers J, Rochette F, Bulcke J. Pulmonary function in moderate neuromuscular disease without respiratory complaints. Eur J Respir Dis 1982; 63: 62-67.

23. Schönhofer B, Barchfeld T, Wenzel M, Kohler D. Long term effects of non-invasive mechanical ventilation on pulmonary haemodynamics in patients with chronic respiratory failure. Thorax 2001; 56: 524-528.

24. Siegler D, Zorab PA. The influence of lung volume on gas transfer in scoliosis. Br J Dis Chest 1982; 76 : 44-50.
25. Vallbona C, Spencer WA. The total lung capacity and its subdivisions. J Chronic Dis 1959; 9: 617-635.

26. Faerber I, Liebert PB, Suskind M. Loss of functional residual capacity in poliomyelitis. $J$ Appl Physiol 1962; 17: 289-292.

27. Hapke EJ, Meek JC, Jacobs J. Pulmonary function in progressive muscular dystrophy. Chest 1972; 61: 41-47.

28. Affeldt JE, Whittenberger JL, Mead J, Ferris G. Pulmonary function in convalescent poliomyelitic patients II. The pressure-volume relations of the thorax and lungs of chronic respiratory patients. $N$ Eng J Med 1952; 247: 43-47.

29. Ferris BG, Whittenberger JL, Affeldt JE. Pulmonary function in convalescent poliomyelitis patients I. Pulmonary subdivisions and maximum breathing capacity. N Eng J Med 1952; 246: 919-923.

30. Inkley SC, Oldenburg FC, Vignos PJ. Pulmonary function in Duchenne muscular dystrophy related to stage of disease. Am J Med 1974; 56: 297-305.

31. Laroche CM, Carroll N, Moxham J, Stanley N, Courtenay Evans R, Green M. Diaphragm weakness in Charcot Marie Tooth disease. Thorax 1988; 43: 478-479.

32. Hughes PD, Polkey MI, Moxham J, Green M. Longterm recovery of diaphragm strength in neuralgic amyotrophy. Eur Respir J 1999; 13: 379-384.

33. Arnulf I, Similowski T, Salachas F, et al. Sleep disorders and diaphragmatic function in patients with amyotrophic lateral sclerosis. Am J Crit Care Med 2000; 161: 849-856.

34. Estenne M, Pinet C, De Troyer A. Abdominal muscle strength in patients with tetraplegia. Am J Respir Care Med 2000; 161: 707-712. 